\title{
Ductile failure prediction of U-notched bainitic Functionally Graded Steel specimens using the Equivalent Material Concept combined with the Averaged Strain Energy Density \\ Criterion
}

\author{
H. Salavati ${ }^{1 *}$, H. Mohammadi ${ }^{2}$ \\ ${ }^{1}$ Department of Mechanical Engineering, Shahid Bahonar University of Kerman, Kerman, Iran \\ ${ }^{2}$ Laboratori de Càlcul Numèric (LaCàN), Universitat Politècnica de Catalunya (UPC), \\ Barcelona, Spain
}

\begin{abstract}
In this paper, the ductile fracture of bainitic Functionally Graded Steel (FGS) has been studied. Fracture tests was performed on U-notched specimens made of bainitic FGS under mode I. The averaged Strain Energy Density (SED) criterion combined with Equivalent Material Concept (EMC) was employed to predict the ductile fracture of bainitic FGS. For this purpose, first based on EMC, the mechanical properties of a virtual brittle FGS was obtained. Then the averaged value of SED over a well-defined control volume was calculated by finite element analysis for U-notched virtual brittle FGS. After that, the fracture loads was obtained based on the averaged SED criterion. The agreement between experimental fracture loads and theoretical predictions was good.
\end{abstract}

Keywords: Functionally graded steel, Strain energy density, Equivalent material concept, Unotch, Mode I 


\section{Introduction}

Prediction of fracture in presence of stress concentrator parts such as notch is a significant issue in the field of structural integrity. Different researchers proposed some approaches to predict the fracture of notches [1-10]. A recent approach [11-13] based on the averaged strain energy density (SED) in a structural control volume has attracted serious attention. This criterion was originally proposed for prediction of fracture of brittle and quasi brittle materials and it was applied to different types of notch and different fracture modes [14-21]. Recently, by using the equivalent material concept [22], application of the averaged SED criterion has been extended for prediction of ductile fracture $[23,24]$. As the equivalent material concept suggests, a ductile material having valid fracture toughness is equated with a virtual brittle material having the same elastic modulus and the same fracture toughness, but a different tensile strength. The tensile strength of the equivalent brittle material can be determined by assuming the same values of the tensile strain energy density required for both ductile and virtual brittle materials for crack initiation[22-24]. Recently, the averaged SED criterion was employed to predict the fracture of notched specimens

made of different types of materials such as Polyurethane (PUR) [25,26], tungsten-copper functionally graded material [27-31] and functionally graded steels [32-34].

To predict the fracture of notched specimens made of FGMs by the averaged SED criterion, unlike homogeneous materials for which the outer boundary of the control volume is a circular arc, the strain energy density is averaged over a well-defined control volume which its outer boundary is an oval arc [27-34]. In these works, the notch depth was in brittle or semi-brittle region. Therefore, the strain energy density approach could predict the critical fracture load precisely and it was not necessary to use the equivalent material concept. 
In this paper, ductile fracture of bainitic functionally graded steel is studied. In the experimental program, bainitic FGS was produced by ESR. The experiments was carried out on U-notched specimens under mode I loading condition. In the theoretical section, equivalent material concept combined with the averaged strain energy density criterion in FGMs was employed to predict the ductile fracture of bainitic FGS. The accuracy of the predictions was acceptable.

\section{Experimental procedure}

Fracture experiments were carried out on bainitic functionally graded steel (FGS). The fabrication procedure of this material has been explained in some previous works [32,33]. Nevertheless, for convenience of the readers a brief description of this is presented here. The bainitic FGS obtained from ingots made of ferritic AISI 1020 and austenitic AISI 316L steels. The diameter of the ingots was equal to $45 \mathrm{~mm}$. The chemical composition of the two materials is summarised in Table 1. A single bar of austenitic steel, with an initial length of $210 \mathrm{~mm}$, and a single bar of ferritic steel with an initial length of $150 \mathrm{~mm}$ spot-welded together were used to produce the two-piece electrode for the fabrication of bainitic specimens. Fig. 1 shows the fabrication scheme of the FGS.

During the fabrication process, the electrodes were welded to a steel bar and successively inserted vertically in the ESR furnace (Fig. 2). The furnace contained a $70 \times 70 \mathrm{~mm}^{2}$ squared copper mould. As first step of the process, some slag was inserted in the starter and melt by activating the electrical power. The liquid, generated by the starter during the melting process, filled the plate cavity. Afterwards, other slag was continuously added to the mould with the aim to increase the electrical resistance. The slag was made of 70\% fluoride-calcium and 30\% aluminium-oxide for a total weight of $1.5 \mathrm{~kg}$.

The final ingots were $60 \mathrm{~mm}$ height. By means of a hot hydraulic press (at $980^{\circ} \mathrm{C}$ ), the height of the ingots was reduced to $22 \mathrm{~mm}$. Then, in order to relief the residual stresses, the ingot was heated 
to $500^{\circ} \mathrm{C}$ for 2 hours and it was cooled in the furnace. Before and after the heat treatment, the residual stresses was measured using conventional X-ray diffraction $\sin ^{2} \psi$ technique with a PANalytical X'Pert PRO MPD instrument. Fig. 3 shows the heat-treated specimen in the XRD instrument. The residual stresses was reduced by $90 \%$ after the heat treatment.

The final height of $18 \mathrm{~mm}$ was reached by machining and grinding.

Vickers hardness tests were carried out using 50 Kgf weight. Fig. 4 shows the Vickers microhardness profile of the $\alpha \beta \gamma$ composite.

The $\alpha \beta \gamma$ specimens drawn from the ingots were characterized by $90 \mathrm{~mm}$ in length, $18 \mathrm{~mm}$ in width and $9 \mathrm{~mm}$ in the thickness direction. The geometry is in agreement with the main standard in force (ASTM E1820) for the crack arrester configuration. A U-notch was drawn from ferritic steel side of each specimen with a notch root radius of $1 \mathrm{~mm}$. Three different notch depths of $9 \mathrm{~mm}, 11 \mathrm{~mm}$ and $14 \mathrm{~mm}$ were considered in the experiments.

To measure the critical fracture load, three-point bending (TPB) load was used. The span length between two supports was set to be equal to $72 \mathrm{~mm}$. The load was applied normally to the interface layers at the notch bisector line in order to obtain mode I loading condition (Fig. 5). The tests were performed by a ZWICK 1494 testing machine under load displacement control with constant displacement-rate of $1 \mathrm{~mm} / \mathrm{min}$. Fig. 6 shows a U-notched specimen under three-point bending test. The load-displacement curves were recorded and used to obtain the critical fracture load.

\section{Mechanical properties}

The mechanical properties of single phase steels present in the considered FGSs are summarized in Table $2[32,33,35,36]$. As is stated in [33], the thickness of the bainitic layer is approximately equal to $2 \mathrm{~mm}$. In addition, the thickness of $\alpha$ and $\gamma$ graded regions are $2.5 \mathrm{~mm}$ and $3.5 \mathrm{~mm}$, respectively. Moreover, the thickness of the original ferritic $(\dot{\alpha})$ and the original austenitic layers 
$(\dot{\gamma})$ are $4.5 \mathrm{~mm}$ and $5.5 \mathrm{~mm}$, respectively. The mechanical properties (ultimate tensile strength and plain strain fracture toughness) of $\alpha$ and $\gamma$ graded regions can be described by using exponential function as follow:

$$
\begin{aligned}
& \sigma_{u t}(x)_{(\alpha)}=\left(\sigma_{u t}\right)_{\alpha_{0}} \cdot e^{\frac{x-4.5}{2.5} \ln \frac{\left(\sigma_{u t}\right)_{\beta}}{\left(\sigma_{u t}\right)_{0}}} \\
& \sigma_{u t}(x)_{(\gamma)}=\left(\sigma_{u t}\right)_{\beta} \cdot e^{\frac{x-9}{3.5} \cdot \ln \frac{\left(\sigma_{u t}\right)_{\gamma_{0}}}{\left(\sigma_{u t}\right)_{\beta}}} \\
& K_{I c}(x)_{(\alpha)}=\left(K_{I c}\right)_{\alpha_{0}} \cdot e^{\frac{x-4.5}{2.5} \ln \frac{\left(K_{I c}\right)_{\beta}}{\left(K_{I c} \alpha_{0}\right.}} \\
& K_{I c}(x)_{(\gamma)}=\left(K_{I c}\right)_{\beta} \cdot e^{\frac{x-9}{3.5} \ln \frac{\left(K_{I c}\right)_{\gamma_{0}}}{\left(K_{I c}\right)_{\beta}}}
\end{aligned}
$$

where $\left(\sigma_{u t}\right)_{\alpha_{0}},\left(\sigma_{u t}\right)_{\beta}$ and $\left(\sigma_{u t}\right)_{\gamma_{0}}$ are the ultimate tensile strength corresponding to $\alpha_{0}, \beta$ and $\gamma_{0}$, respectively and $\left(K_{I c}\right)_{\alpha_{0}},\left(K_{I c}\right)_{\beta}$ and $\left(K_{I c}\right)_{\gamma_{0}}$ are the plain strain fracture toughness corresponding to $\alpha_{0}, \beta$ and $\gamma_{0}$, respectively as shown in Table 2 .

\section{Fracture criterion based on averaged SED in FGMs and equivalent material concept}

The averaged SED criterion states that brittle fracture occurs when the averaged value of the SED over a well-defined control volume reaches a critical value $\mathrm{W}_{\mathrm{c}}[13] . \mathrm{W}_{\mathrm{c}}$ is a material-dependent value which is independent of notch geometry. For brittle materials, $\mathrm{W}_{\mathrm{c}}$ can be evaluated as follow[13]:

$$
\frac{\sigma_{u t}^{2}}{2 E}
$$

For a U-notch under mode I loading, the control volume assumes the crescent shape which is centered in relation to the notch bisector line as shown in Fig. 7. $R_{c}$ is the critical length which is measured along the notch bisector line.

The critical length $\left(\mathrm{R}_{\mathrm{c}}\right)$ can be evaluated as follow under plane strain conditions[37,38]: 


$$
R_{c}=\frac{(1+v)(5-8 v)}{4 \pi}\left(\frac{K_{I c}}{\sigma_{u t}}\right)^{2}
$$

where $\mathrm{K}_{\mathrm{Ic}}$ is the fracture toughness, $\sigma_{\mathrm{ut}}$ is the ultimate tensile stress and $v$ is the Poisson's ratio. As is shown in Fig. 7 the outer radius of the control volume in a U-notch is equal to $R_{c}+\rho / 2$ where $\rho$ is the notch root radius.

For an embedded crack or notch in a FGM specimen, it is assumed that the properties of the material in which the crack or notch tip is placed plays a key role in initiation of fracture of the specimen. Accordingly, the criterion states that fracture initiates when the averaged value of SED over a well-defined control volume reaches the corresponding to the notch tip value of $\mathrm{W}_{\mathrm{c}}$. In a nonhomogeneous medium with a smooth unidirectional variation of mechanical properties in the $\mathrm{x}$-direction (along the notch depth), the value of $\mathrm{W}_{\mathrm{c}}$ can be determined as follow $[33,31]$ :

$$
\frac{\sigma_{u t}^{2}(a)}{2 E(a)}
$$

where $a$ is the notch depth.

Unlike homogeneous materials, in FGMs due to a gradual change in material properties, the outer boundary of control volume is no longer a circular arc, but rather an oval arc is assumed. This notion has been used in a number of previous studies on fracture of notched specimens made of FGMs $[32,31,39,27-30]$. For a U-notched FGM specimen with a material variation in the $\mathrm{x}$ direction under mode I, the outer boundary can be determined by a numerical approach using the following equations. For more details please see Refs. [32,33].

$$
\begin{aligned}
& x=a-\rho / 2+\left(R_{c}(x)+\rho / 2\right) \cos (\theta) \\
& y=\left(R_{c}(x)+\rho / 2\right) \sin (\theta) \\
& R_{c}(x)=\frac{(1+v)(5-8 v)}{4 \pi}\left(\frac{K_{I c}(x)}{\sigma_{u t}(x)}\right)^{2}
\end{aligned}
$$


where $\mathrm{x}$ and $\mathrm{y}$ are the coordinates of a point on the outer boundary, $\theta$ is the corresponding angle to that point (see Fig. 8), $a$ is notch depth and $R_{c}(x)$ is the critical length as a function of $\mathrm{x}-$ coordinate.

The mentioned criterion has been used in different investigations to predict the fracture of notched specimens made of functionally graded materials $[32,33,31,27-30]$. However, in this study, as the notch root has been located in a very ductile region, the mentioned criterion cannot give reasonably accurate results. So, the mentioned criterion is modified by using equivalent material concept (EMC) $[22,23,40]$. As is proposed by Torabi [22], a ductile material having valid fracture toughness is equated with a virtual brittle material having the same elastic modulus and the same fracture toughness, but different tensile strength. The tensile strength of the equivalent brittle material can be determined by assuming the same values of the tensile strain energy density required for both ductile and virtual brittle materials for crack initiation.

$$
\frac{\sigma_{u t_{-} E M C}^{2}}{2 E}=(S E D)_{d u c t i l e}
$$

In Eq. 9, $\sigma_{\text {ut_EMC }}$ is ultimate tensile strength of the virtual brittle material, $\mathrm{E}$ is the elasticity modulus, and (SED)ductile is the area under stress-strain curve of the ductile material until necking. In this paper, the bainitic FGS has been modelled as a virtual brittle one. To this end, the ultimate tensile strength of single phase steels in the virtual brittle FGS was calculated by using the values of the area under stress-strain curves provided in Table 2. The values of the ultimate tensile strength of single phase steels in the virtual brittle FGS ( $\sigma_{\text {ut }}$ EMC $)$ has been summarized in Table 2. In the virtual brittle FGS, the ultimate tensile strength of $\alpha$ and $\gamma$ graded regions can be described

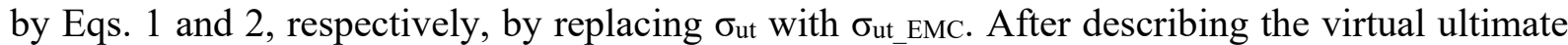
tensile strengths of each point, the control volume in the virtual brittle FGS can be determined by Eq. 8 by replacing $\sigma_{u t}$ with $\sigma_{u t}$ EMC. 


\section{Application of EMC-ASED to predict the fracture loads of U-notched FGS specimens and results}

In order to obtain the averaged value of SED over the control volume, some finite element analyses were carried out by using ABAQUS software version 6.11. It should be noted that the Young's modulus $(E=207 \mathrm{GPa})$ and the Poisson's ratio $(v=0.33)$ have been assumed to be constant along the specimen width. All the finite element analyses were carried out under plane strain conditions and linear elastic hypothesis. Eight-node elements were used in analyses.

By applying an arbitrary load in ABAQUS the fracture load can be obtained as follow:

$$
\frac{F_{a p p}}{F_{t h}}=\sqrt{\frac{S E D}{W_{c}}}
$$

Where $F_{\text {app }}$ is the applied load in the numerical model, $F_{\text {th }}$ is the theoretical fracture load, SED is the averaged value of strain energy density over the control volume and $\mathrm{W}_{\mathrm{c}}$ is the critical value of strain energy density corresponding to the notch tip.

The notch depths from $8 \mathrm{~mm}$ to $15 \mathrm{~mm}$ have been considered in numerical analyses in order to assess the effect of notch depth on fracture load. Fig. 9 a,b Shows the contour lines of maximum principal stress and strain energy density obtained from finite element analyses.

Table 3 summarizes the theoretical predictions and experimental results. As can be seen from the table, the agreement is satisfactory. The experimental and theoretical results have been depicted in Fig. 10. As can be seen from Fig. 10, the experimental and theoretical results follow the same trend. 


\section{Conclusion}

In this paper, equivalent material concept in conjunction with the averaged strain energy density criterion in FGMs was employed to predict the ductile fracture of bainitic functionally graded material. The accuracy of the predictions was reasonable.

\section{References}

[1] T. Lin, A.G. Evans, R.O. Ritchie, Statistical analysis of cleavage fracture ahead of sharp cracks and rounded notches, Acta Metall. 34 (1986) 2205-2216. doi:https://doi.org/10.1016/0001-6160(86)90166-5.

[2] V. V Novozhilov, On a necessary and sufficient criterion for brittle strength: PMM vol. 33, $\mathrm{n} \circ 2, \quad 1969, \quad$ pp. 212-222, J. Appl. Math. Mech. 33 (1969) 201-210. doi:https://doi.org/10.1016/0021-8928(69)90025-2.

[3] A. Seweryn, Brittle fracture criterion for structures with sharp notches, Eng. Fract. Mech. 47 (1994) 673-681. doi:http://dx.doi.org/10.1016/0013-7944(94)90158-9.

[4] D. Taylor, Predicting the fracture strength of ceramic materials using the theory of critical distances, Eng. $\quad$ Fract. Mech. $71 \quad$ (2004) 2407-2416. doi:https://doi.org/10.1016/j.engfracmech.2004.01.002.

[5] D. Leguillon, A criterion for crack nucleation at a notch in homogeneous materials, Comptes Rendus l'Académie Des Sci. - Ser. IIB - Mech. 329 (2001) 97-102. doi:https://doi.org/10.1016/S1620-7742(01)01302-2.

[6] F.J. Gómez, M. Elices, A. Valiente, Cracking in PMMA containing U-shaped notches, Fatigue Fract. Eng. Mater. Struct. 23 (2000) 795-803. doi:10.1046/j.14602695.2000.00264.x.

[7] F.J. Gómez, M. Elices, J. Planas, The cohesive crack concept: application to PMMA at -60 
${ }^{\circ} \mathrm{C}, \quad$ Eng. $\quad$ Fract. $\quad$ Mech. $72 \quad$ (2005) 1268-1285. doi:http://dx.doi.org/10.1016/j.engfracmech.2004.09.005.

[8] M. Elices, G. V Guinea, J. Gómez, J. Planas, The cohesive zone model: advantages, limitations and challenges, Eng. Fract. Mech. 69 (2002) 137-163. doi:http://dx.doi.org/10.1016/S0013-7944(01)00083-2.

[9] M.R. Ayatollahi, A.R. Torabi, Investigation of mixed mode brittle fracture in rounded-tip V-notched components, Eng. Fract. Mech. $77 \quad$ (2010) 3087-3104. doi:http://dx.doi.org/10.1016/j.engfracmech.2010.07.019.

[10] C.-K. Oh, Y.-J. Kim, J.-H. Baek, Y.-P. Kim, W.-S. Kim, Ductile failure analysis of API X65 pipes with notch-type defects using a local fracture criterion, Int. J. Press. Vessel. Pip. 84 (2007) 512-525. doi:https://doi.org/10.1016/j.ijpvp.2007.03.002.

[11] P. Lazzarin, R. Zambardi, A finite-volume-energy based approach to predict the static and fatigue behavior of components with sharp V-shaped notches, Int. J. Fract. 112 (2001) 275298. doi:10.1023/a:1013595930617.

[12] P. Lazzarin, F. Berto, Some Expressions for the Strain Energy in a Finite Volume Surrounding the Root of Blunt V-notches, Int. J. Fract. 135 (2005) 161-185. doi:10.1007/s10704-005-3943-6.

[13] F. Berto, P. Lazzarin, Recent developments in brittle and quasi-brittle failure assessment of engineering materials by means of local approaches, Mater. Sci. Eng. R Reports. 75 (2014) 1-48. doi:http://dx.doi.org/10.1016/j.mser.2013.11.001.

[14] F. Berto, P. Lazzarin, C. Marangon, Brittle fracture of U-notched graphite plates under mixed mode loading, Mater. Des. $41 \quad$ (2012) 421-432. doi:http://dx.doi.org/10.1016/j.matdes.2012.05.022. 
[15] A.R. Torabi, A. Campagnolo, F. Berto, Local strain energy density to predict mode II brittle fracture in Brazilian disk specimens weakened by V-notches with end holes, Mater. Des. 69 (2015) 22-29.

[16] F.J. Gómez, M. Elices, F. Berto, P. Lazzarin, Local strain energy to assess the static failure of U-notches in plates under mixed mode loading, Int. J. Fract. 145 (2007) 29-45. doi:10.1007/s10704-007-9104-3.

[17] P. Lazzarin, F. Berto, M.R. Ayatollahi, Brittle failure of inclined key-hole notches in isostatic graphite under in-plane mixed mode loading, Fatigue Fract. Eng. Mater. Struct. 36 (2013) 942-955. doi:10.1111/ffe.12057.

[18] F. BERTO, P. LAZZARIN, A. KOTOUSOV, L.P. POOK, Induced out-of-plane mode at the tip of blunt lateral notches and holes under in-plane shear loading, Fatigue Fract. Eng. Mater. Struct. 35 (2012) 538-555. doi:10.1111/j.1460-2695.2011.01647.x.

[19] F. Berto, P. Lazzarin, M.R. Ayatollahi, Brittle fracture of sharp and blunt V-notches in isostatic graphite under pure compression loading, Carbon N. Y. 63 (2013) 101-116. doi:http://dx.doi.org/10.1016/j.carbon.2013.06.045.

[20] M.R. Ayatollahi, F. Berto, P. Lazzarin, Mixed mode brittle fracture of sharp and blunt Vnotches in polycrystalline graphite, Carbon N. Y. 49 (2011) 2465-2474. doi:http://dx.doi.org/10.1016/j.carbon.2011.02.015.

[21] F. Berto, P. Lazzarin, M.R. Ayatollahi, Brittle fracture of sharp and blunt V-notches in isostatic graphite under torsion loading, Carbon N. Y. 50 (2012) 1942-1952. doi:https://doi.org/10.1016/j.carbon.2011.12.045.

[22] A.R. Torabi, Estimation of tensile load-bearing capacity of ductile metallic materials weakened by a V-notch: The equivalent material concept, Mater. Sci. Eng. A. 536 (2012) 
249-255. doi:https://doi.org/10.1016/j.msea.2012.01.007.

[23] A.R. Torabi, F. Berto, S.M.J. Razavi, Ductile failure prediction of thin notched aluminum plates subjected to combined tension-shear loading, Theor. Appl. Fract. Mech. (2017). doi:https://doi.org/10.1016/j.tafmec.2017.05.003.

[24] A.R. Torabi, F. Berto, A. Campagnolo, J. Akbardoost, Averaged strain energy density criterion to predict ductile failure of U-notched Al 6061-T6 plates under mixed mode loading, Theor. Appl. Fract. Mech. $91 \quad$ (2017) 86-93. doi:https://doi.org/10.1016/j.tafmec.2017.04.010.

[25] R. Negru, L. Marsavina, H. Filipescu, C. Căplescu, T. Voiconi, Assessment of brittle fracture for $\{\mathrm{PUR}\}$ materials using local strain energy density and theory of critical distances, Theor. Appl. Fract. Mech. $79 \quad$ (2015) 62-69. doi:http://dx.doi.org/10.1016/j.tafmec.2015.07.011.

[26] L. Marsavina, F. Berto, R. Negru, D.A. Serban, E. Linul, An engineering approach to predict mixed mode fracture of PUR foams based on ASED and micromechanical modelling, Theor. Appl. $\quad$ Fract. $\quad$ Mech. $91 \quad$ (2017) 148-154. doi:https://doi.org/10.1016/j.tafmec.2017.06.008.

[27] H. Mohammadi, H. Salavati, M.R. Mosaddeghi, A. Yusefi, F. Berto, Local strain energy density to predict mixed mode $\mathrm{I}+\{\mathrm{II}\}$ fracture in specimens made of functionally graded materials weakened by V-notches with end holes, Theor. Appl. Fract. Mech. (2017). doi:https://doi.org/10.1016/j.tafmec.2017.05.009.

[28] H. Mohammadi, H. Salavati, Y. Alizadeh, A. Abdullah, F. Berto, Fracture investigation of U-notch made of tungsten-copper functionally graded materials by means of strain energy density, Fatigue $\{\&\} \quad$ Fract. Eng. Mater. $\{\&\}$ Struct. (2017) n/a----n/a. 
doi:10.1111/ffe.12616.

[29] H. Mohammadi, H. Salavati, Y. Alizadeh, F. Berto, S. V Panin, Fracture investigation of V-notch made of tungsten-copper functionally graded materials, Phys. Mesomech. 20 (2017) 457-464. doi:10.1134/S1029959917040117.

[30] H. Salavati, H. Mohammadi, A. Yusefi, F. Berto, Fracture assessment of V-notched specimens with end holes made of tungsten-copper functionally graded material under mode I loading, Theor. Appl. Fract. Mech. (2017). doi:https://doi.org/10.1016/j.tafmec.2017.06.013.

[31] H. Mohammadi, H. Salavati, Y. Alizadeh, F. Berto, Prevalent mode $\{\{\} I I\{\}\}$ fracture assessment of inclined U-notched specimens made of tungsten-copper functionally graded $\begin{array}{llll}\text { material, } & \text { Theor. }\end{array}$ doi:http://dx.doi.org/10.1016/j.tafmec.2017.01.010.

[32] H. Salavati, Y. Alizadeh, F. Berto, Effect of notch depth and radius on the critical fracture load of bainitic functionally graded steels under mixed mode I + II loading, Phys. Mesomech. 17 (2014) 178-189. doi:10.1134/s1029959914030023.

[33] H. Salavati, Y. Alizadeh, F. Berto, Fracture Assessment of Notched Bainitic Functionally Graded Steels under Mixed Mode (I+ II) Loading, Phys. Mesomech. 18 (2015) 307-325.

[34] S. Mehran, S. Rouhi, B. Ramzani, E. Barati, Fracture analysis of functionally graded materials with U- and V-notches under mode I loading using the averaged strain-energy density criterion, Fatigue Fract. Eng. Mater. Struct. 35 (2012) 614-627. doi:10.1111/j.14602695.2011.01655.x.

[35] J.A. Mohandesi, R.P. Namin, M.H. Shahosseinie, Tensile behavior of functionally graded steels produced by electroslag remelting, Metall. Mater. Trans. A. 37 (2006) 2125-2132. 
doi:10.1007/BF02586133.

[36] A. Nazari, J.A. Mohandesi, S. Riahi, Modified Modeling Fracture Toughness of Functionally Graded Steels in Crack Divider Configuration, Int. J. Damage Mech. 20 (2011) 811-830. doi:10.1177/1056789510382851.

[37] Z. Yosibash, A. Bussiba, I. Gilad, Failure criteria for brittle elastic materials, Int. J. Fract. 125 (2004) 307-333. doi:10.1023/B:FRAC.0000022244.31825.3b.

[38] F. Berto, Fatigue and fracture assessment of notched components by means of the Strain Energy Density, Eng. Fract. Mech. (2016). doi:http://dx.doi.org/10.1016/j.engfracmech.2016.04.021.

[39] E. Barati, J. Aghazadeh Mohandesi, Y. Alizadeh, The effect of notch depth on J-integral and critical fracture load in plates made of functionally graded aluminum-silicone carbide composite with U-notches under bending, Mater. Des. 31 (2010) 4686-4692. doi:http://dx.doi.org/10.1016/j.matdes.2010.05.025.

[40] A.R. Torabi, A. Campagnolo, F. Berto, Mixed mode I/II crack initiation from U-notches in Al 7075-T6 thin plates by large-scale yielding regime, Theor. Appl. Fract. Mech. (2016). doi:http://dx.doi.org/10.1016/j.tafmec.2016.08.002. 


\section{Figure captions:}

Fig. 1. The fabrication scheme of the U-notched FGS specimens

Fig. 2. ESR device used for fabrication of the specimens

Fig. 3. XRD instrument used for measurement of the residual stress

Fig. 4. Vickers micro-hardness profile versus width in $\alpha \beta \gamma$ FGS

Fig. 5. Notched beam specimen geometries (dimensions are in millimetres)

Fig.6. A U-notched specimen under three-point bending test

Fig. 7. Control volume of a U-notched homogeneous specimen under mode I

Fig. 8. Control volume of a U-notched FGM specimen under mode I

Fig. 9. Contour lines of (a) maximum principal stress and (b) strain energy density in the case notch depth $a=14 \mathrm{~mm}$

Fig. 10. Comparison between experimental results and numerical predictions 
Figures:

Fig. 1

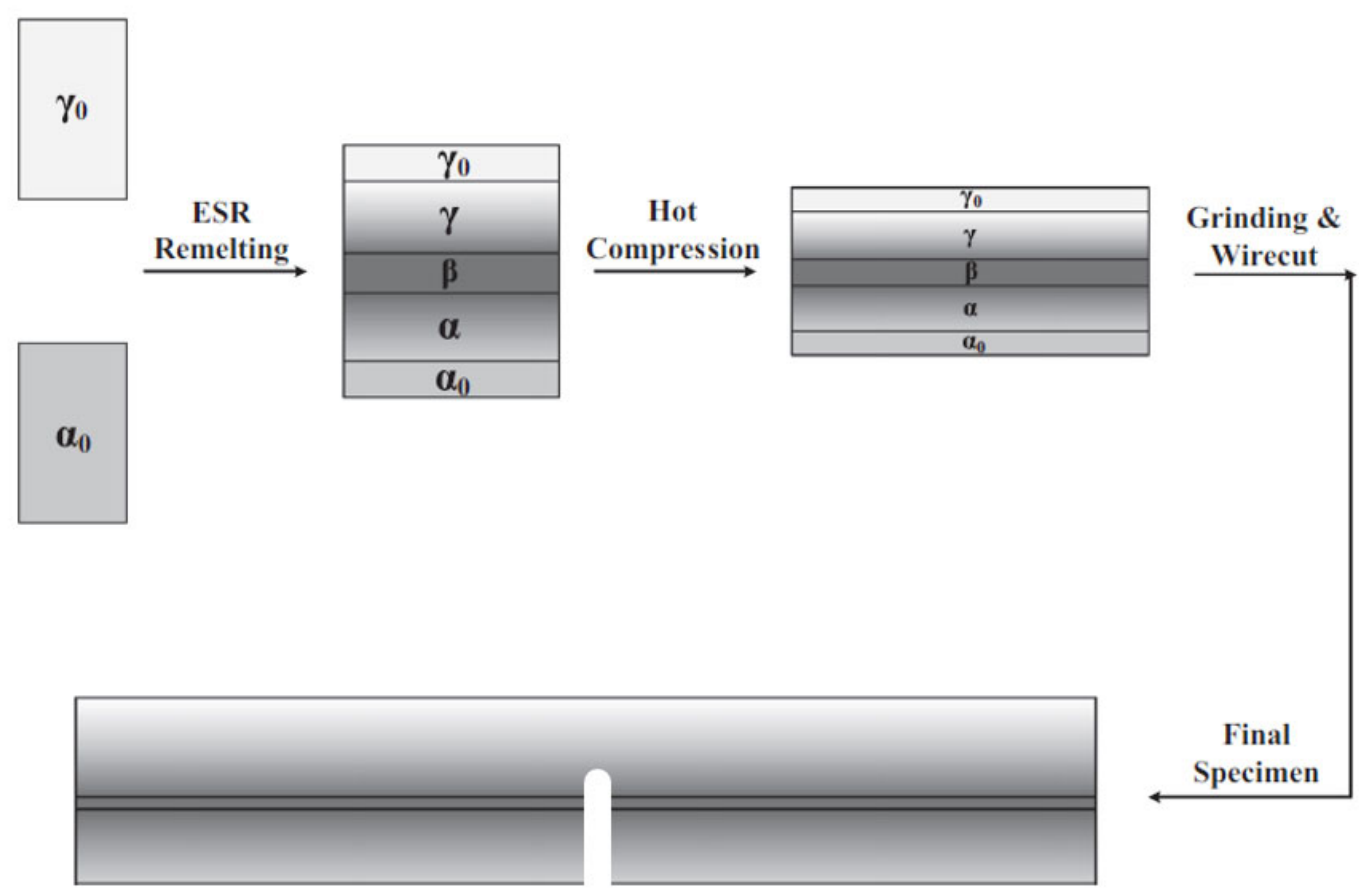


Fig. 2

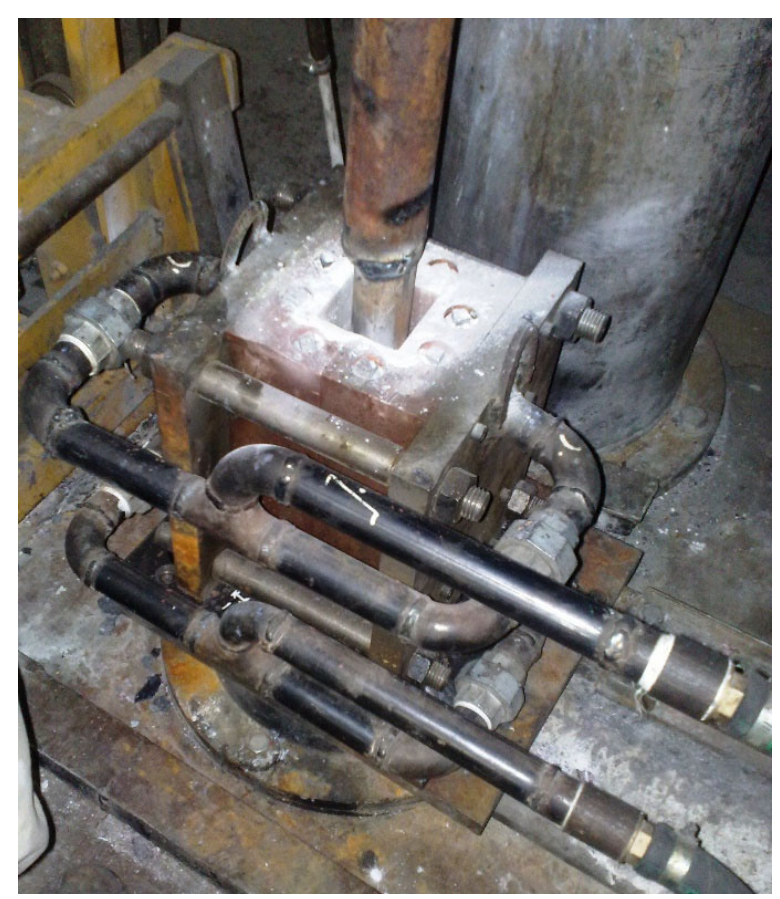


Fig. 3

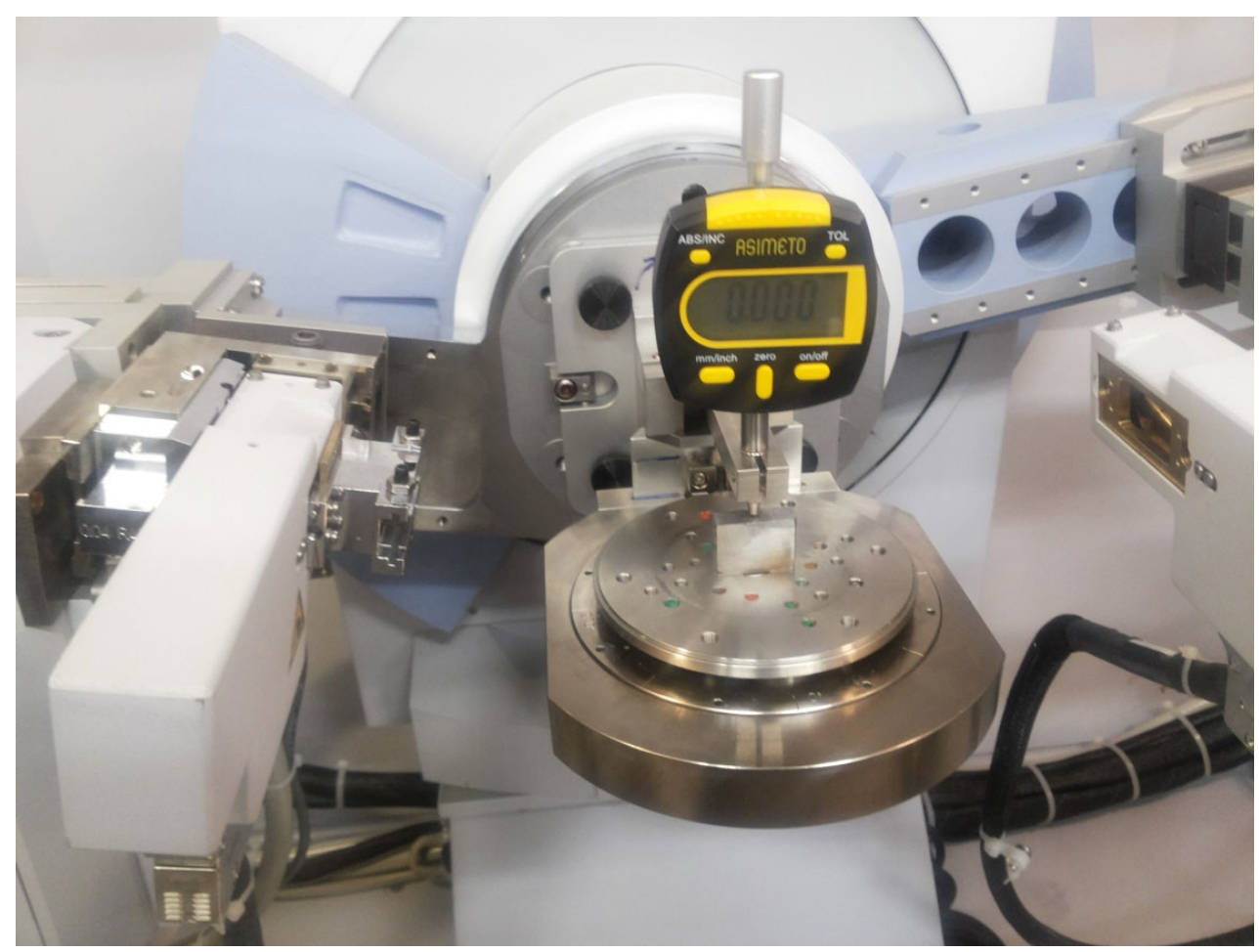


Fig. 4

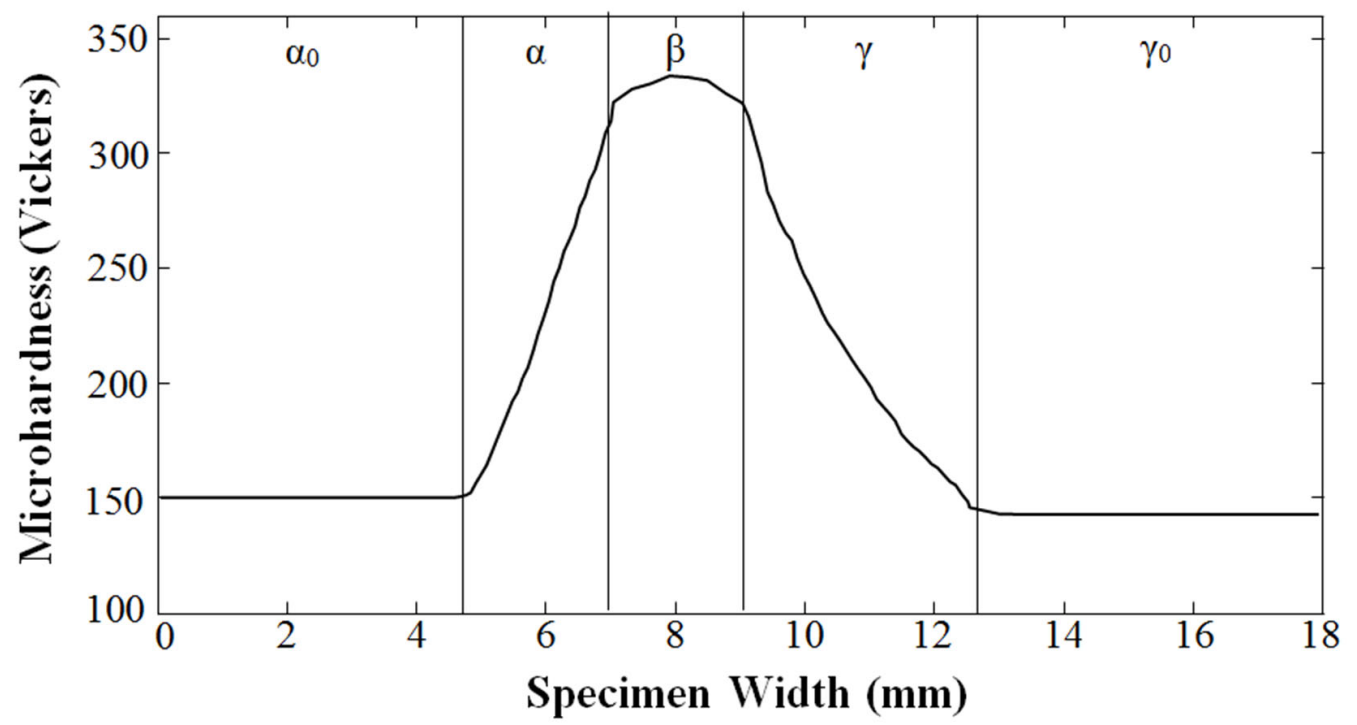


Fig. 5

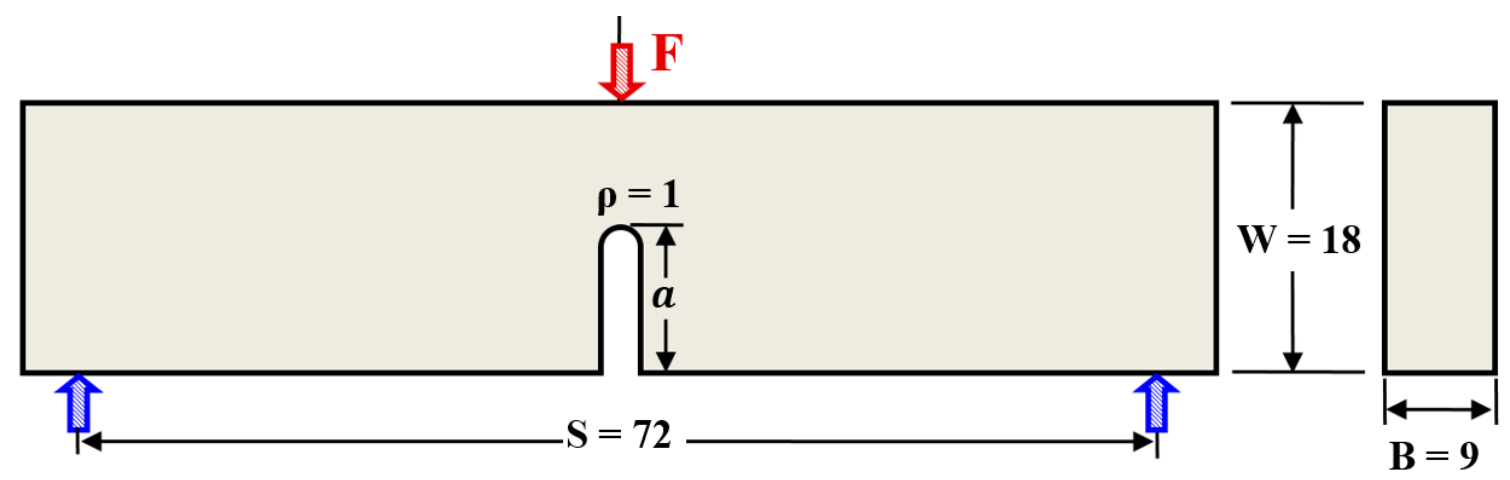


Fig. 6

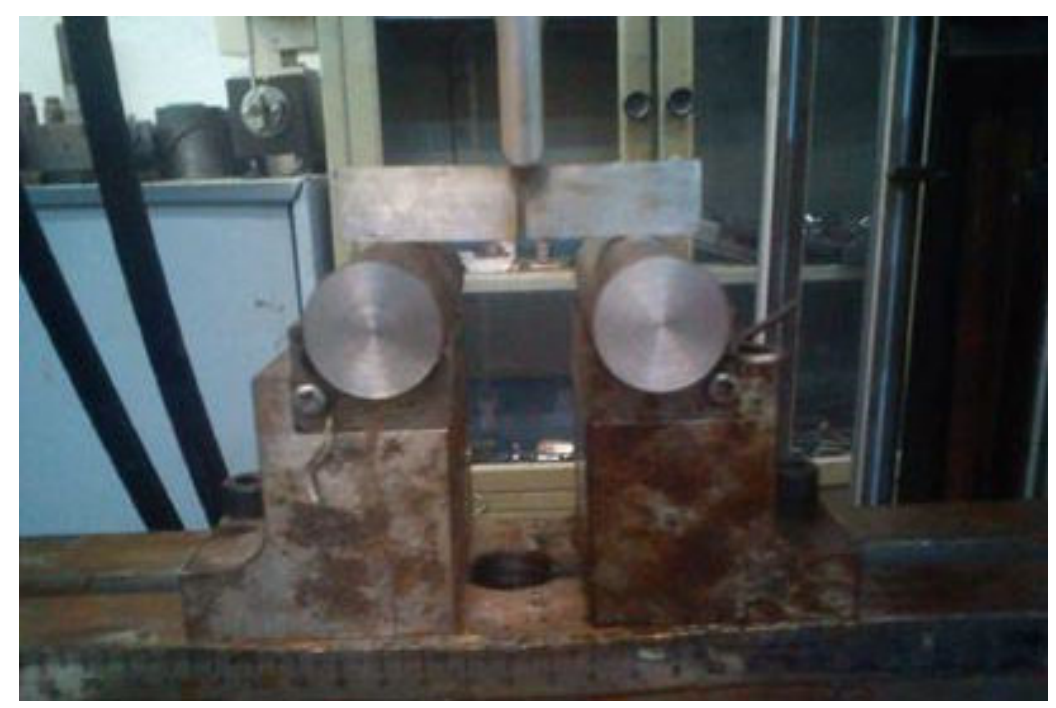


Fig. 7

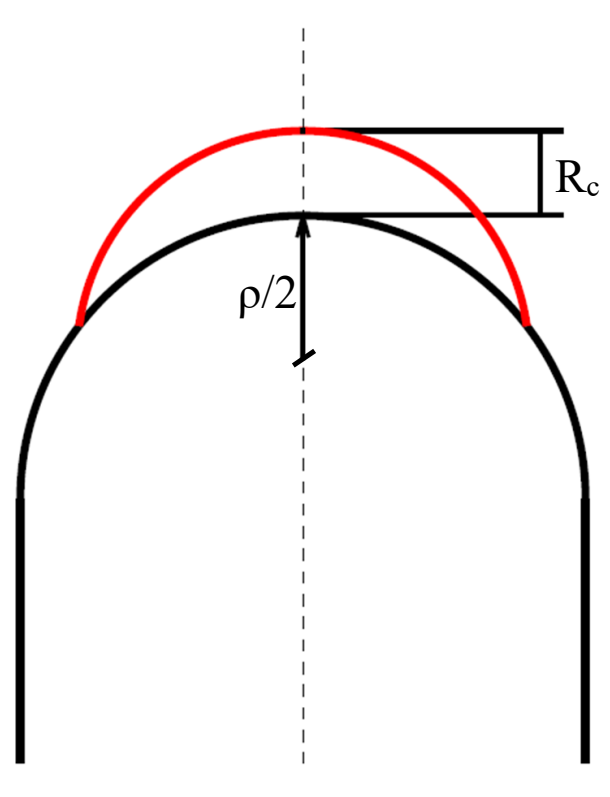


Fig. 8

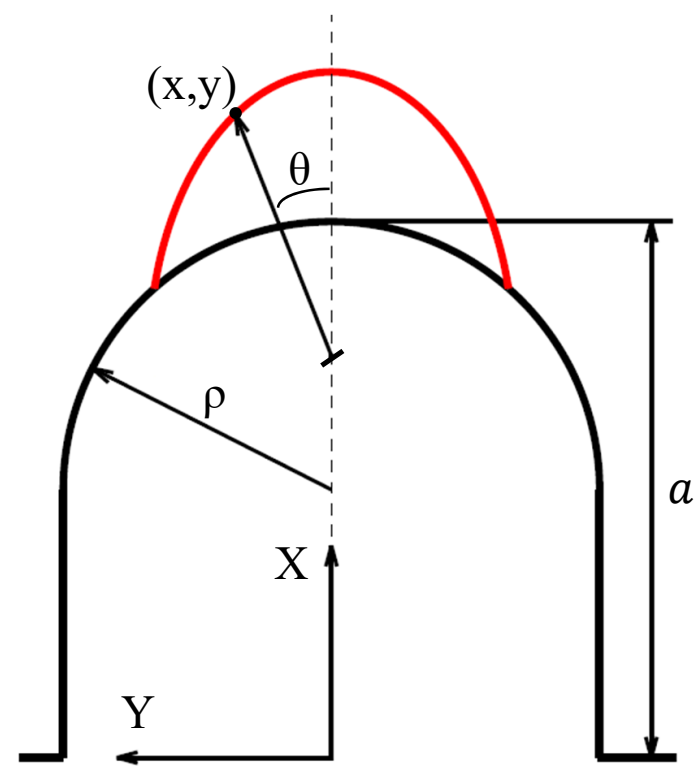


Fig. 9

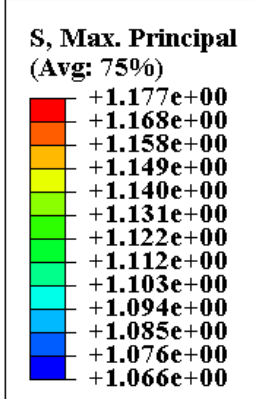

(a)

ESEDEN

(Avg: 75\%)

(b)

$++2.921 \mathrm{e}-06$

$+2.877 \mathrm{e}-06$

$+2.833 \mathrm{e}-06$
$+2.789 \mathrm{e}-06$

$+2.789 \mathrm{e}-06$
$+2.745 \mathrm{e}-06$

$+2.745 \mathrm{e}-06$

$+2.701 \mathrm{e}-06$

$+2.657 \mathrm{e}-06$

$+2.613 \mathrm{e}-06$

$+2.569 \mathrm{e}-06$

$+2.525 \mathrm{e}-06$

$+2.481 \mathrm{e}-06$

$+2.437 \mathrm{e}-06$
$+2.393 \mathrm{e}-06$
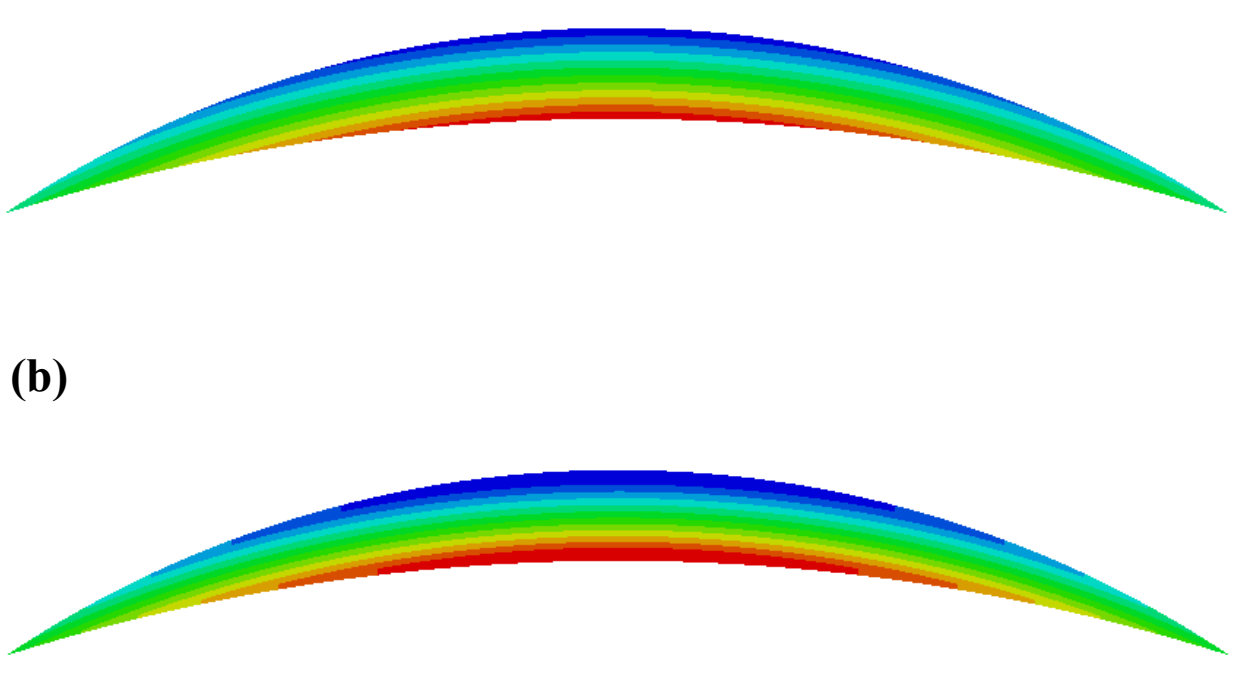
Fig. 10

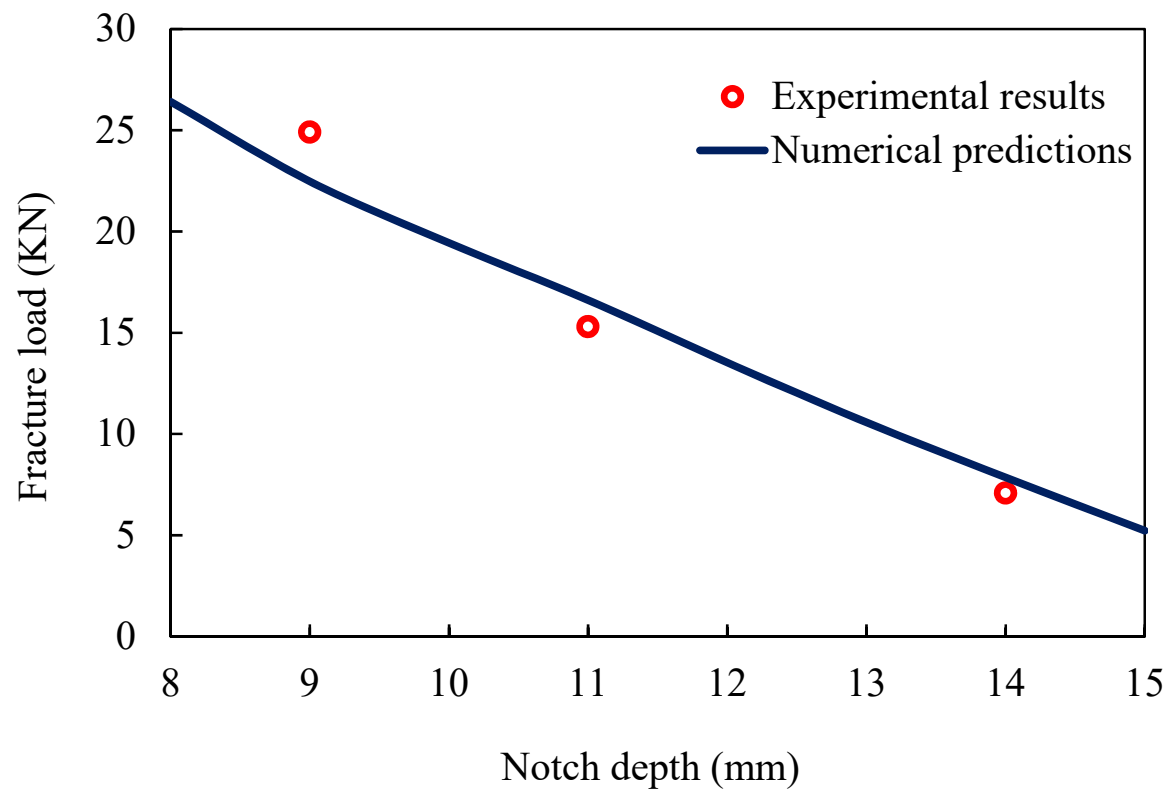


Tables:

Table 1. Chemical composition of original ferritic and austenitic steels

\begin{tabular}{|c|c|c|c|c|c|c|c|c|c|}
\hline & \%C & \%Ni & \%Cr & \%Mo & \%Cu & \%Si & \%Mn & \%S & \%P \\
\hline AISI1020 $(\dot{\gamma})$ & 0.01 & 9.58 & 16.69 & 1.89 & 0.43 & 0.53 & 1.5 & 0.04 & 0.04 \\
\hline 316L $(\dot{\alpha})$ & 0.11 & 0.07 & 0.12 & 0.02 & 0.29 & 0.19 & 0.63 & 0.08 & 0.01 \\
\hline
\end{tabular}


Table 2. Mechanical properties of single phase steels present in the considered FGSs $[32,35,36]$

\begin{tabular}{|c|c|c|c|c|c|c|c|}
\hline & $\begin{array}{c}\text { Yield Stress } \\
\sigma_{\mathbf{y}}(\mathrm{MPa})\end{array}$ & $\begin{array}{c}\text { Ultimate } \\
\text { tensile } \\
\text { strength } \\
\sigma_{\text {ut }}(\mathrm{MPa})\end{array}$ & $\begin{array}{c}\text { Fracture } \\
\text { toughness } \\
\text { K Ic }_{\text {IMPa.m }}\left(\mathrm{MPa}^{0.5}\right)\end{array}$ & $\begin{array}{c}\text { Poisson's ratio } \\
\text { v }\end{array}$ & $\begin{array}{c}\text { Elasticity } \\
\text { modulus } \\
\text { E (GPa) }\end{array}$ & Area under stress-strain curve (MPa) & $\sigma_{\text {ut_EMC }}(\mathbf{M P a})$ \\
\hline Ferrite & 245 & 425 & 45.72 & 0.33 & 207 & 71.4 & 5437 \\
\hline Bainite & 1025 & 1125 & 82.08 & 0.33 & 207 & 120.2 & 7054 \\
\hline Austenite & 200 & 480 & 107.77 & 0.33 & 207 & 155.6 & 8026 \\
\hline
\end{tabular}


Table 3. Theoretical values of SED and fracture load $\left(\mathrm{F}_{\text {th }}\right)$ together with experimental results ( $F_{\exp }$ (The SED in this table has been evaluated by applying $\mathrm{F}=1 \mathrm{~N}$ in finite element models)

\begin{tabular}{|c|c|c|c|c|c|c|c|}
\hline $\mathbf{a}(\mathbf{m m})$ & $\begin{array}{c}\boldsymbol{\sigma}_{\text {ut_EMC }} \\
\mathbf{( M P a )}\end{array}$ & $\mathbf{E}(\mathbf{G P a})$ & $\begin{array}{c}\mathbf{W}_{\mathbf{C} \text { EMC }} \\
\left(\mathbf{M J} / \mathbf{m}^{3}\right)\end{array}$ & $\begin{array}{c}\mathbf{S E D} \\
\left(\mathbf{J} / \mathbf{m}^{\mathbf{3}}\right)\end{array}$ & $\mathbf{F}_{\text {th }}(\mathbf{K N})$ & $\mathbf{F}_{\text {exp }}(\mathbf{K N})$ & $\mathbf{F}_{\text {exp }} / \mathbf{F}_{\text {th }}$ \\
\hline 8 & 7054 & 207 & 120.2 & 0.172 & 26.4 & & \\
\hline 9 & 7054 & 207 & 120.2 & 0.238 & 22.5 & 24.9 & 1.11 \\
\hline 10 & 7319 & 207 & 129.4 & 0.343 & 19.4 & & \\
\hline 11 & 7594 & 207 & 139.3 & 0.505 & 16.6 & 15.3 & 0.92 \\
\hline 12 & 7879 & 207 & 150.0 & 0.819 & 13.5 & & \\
\hline 13 & 8026 & 207 & 155.6 & 1.391 & 10.6 & & \\
\hline 14 & 8026 & 207 & 155.6 & 2.523 & 7.9 & 7.08 & 0.90 \\
\hline 15 & 8026 & 207 & 155.6 & 5.697 & 5.2 & & \\
\hline
\end{tabular}

